\title{
Impact of energy storage systems on the management of fault current at LV network with high penetration of distributed generation
}

\author{
K. N. Bangash ${ }^{\mathrm{a}}$, M. E. A. Farrag ${ }^{\mathrm{b}}$, A. H. Osman ${ }^{\mathrm{c} *}$ \\ ${ }^{a}$ K.N. Bangash, American University of Sharjah, Sharjah, 26666, UAE \\ ${ }^{b}$ M.E.A. Farrag, Glasgow Caledonian University, Glasgow, G4 OBA, UK \\ ${ }^{c}$ A.H. Osman, American University of Sharjah, Sharjah, 26666, UAE
}

\begin{abstract}
Penetration level of renewable energy such as solar and wind power into the grid is sharply increasing worldwide. This paper investigates the impact of the increasing level of Distributed Generation (DG) on the distribution network protection. Studies were commenced to mitigate the effect of small scale embedded generation (SSEG) on the system fault levels. Residential DG penetration level is modelled on the UK typical Low Voltage (LV) network considering the fault level stability limits. Based on penetration level of DG energy storages in the form of battery bank are determined to charge and discharge according to daily load cycle. Short circuit analysis results are compared with the UK passive network to investigate the impact of the DG on the short circuit currents at the distribution transformer. In this study, power flow from the transformer secondary is kept within limits to avoid malfunctioning of relays. The flow of reverse power in the presence of DG is confined by energy storage elements.
\end{abstract}

Keywords: DG penetration, distribution network, energy storage batteries, Electric Vehicles (EVs), fault current, reverse power flow

\section{Introduction}

Smart grid has opened the way for communicating grid events and information between utilities and their customers. This has enabled the use of Demand Response (DR) programs and Distributed Energy Resources (DER) assets in effective and efficient way [1]. In the smart grid environment, electric power generated from renewable DG, such as solar and wind power, can be integrated and coordinated efficiently with the main utility grid. DG can help support the increased demand for electricity, and may improve power generation efficiency and network reliability [2]. However, high penetration of DG may also lead to problems, such as reverse power flow, voltage unbalance, changes in network Short Circuit Level (SCL) and consequently changes in the setting of existing protection systems, particularly in weak distribution networks [3]-[4].

During light loading conditions and high DG power generation, the utility may curtail this energy production to maintain the network stability. This energy curtailment is considered as a waste of energy [5]. Energy storage is required at LV distribution network to store excessive electric energy generated by DG and supply power back during low generation times. This allows the system to run on average load rather than peak load. Energy storage system can also compensate for intermittency of renewable energy. Winter peak demand on the UK grid is currently around $65 \mathrm{GW}$, but by 2050 this will increase six-fold as demand for electric cars and household heating climbs. Energy storage technologies could generate savings of $£ 10$ bn a year by 2050 in the UK [6]. ABB has worked with UK Power Networks, which supplies power to over eight million homes and businesses in the UK, to develop a dynamic energy storage solution. The installation enables renewable energy generated and also ensures compensation of the intermittence of wind power, support power quality in the event of a fault and provides dynamic

\footnotetext{
*Manuscript received March 1, 2017; revised June 4, 2017.

Corresponding author. Tel.: +00971509750233; E-mail address: kbangash@aus.edu/.

doi: 10.12720/sgce.6.3.195-206
} 
voltage control in the distribution system [7].

In Germany, solar power can be generated for 0.12 Euro per kWh. In contrast, utilities currently charge an average of 0.25 Euro for domestic electricity. Solar storage systems can increase on-site consumption by up to $70 \%$. According to EuPD research survey, almost $90 \%$ of solar operators are already thinking about buying an additional storage system [8].

Small size Lithium ion batteries are available in the range 1-10 $\mathrm{kWh}$. Energy storage integrated with PV can maximize consumption of solar energy by using electricity stored during off-peak times [9]. The batteries can be properly charged and discharged to support the frequency when system transfers into islanding mode. Battery storage are used in [10]-[11] to improve the security of supply for grid connected $\mathrm{PV}$, curtail overvoltage problem, peak shaving and to improve transient stability. A study to investigate the interruptions in Europe showed that the storage should ensure a total of 3 hours of autonomy for the users, which will allow the system to cover $90 \%$ of the interruptions [12]. During a fault period, DG along with storage devices connected to the grid can reduce the drop in terminal voltage and the deviation in rotor speed, which can definitely enhance the transient stability of the system [12]. In [13] batteries are used for frequency and voltage control of microgrid. A controller is developed for a CIGRE LV network using DG, Static Compensator (STATCOM) and Battery Storage System (BSS). A controller is designed to control the battery charge/discharge rate and the reactive power flow through the lines in order to improve the power factor [14]. A strategy to shave the peak demand and mitigate the voltage unbalance of the electrical networks using a BSS is developed in [15].

This work investigates the high penetration level of DG and its impacts on fault current contribution and protective relays malfunction. Energy storage batteries are used to confine the flow of short circuit current contributed by DG. The rest of the paper is organized as follows. Section 2 explains the problems related to protective device coordination in systems with high penetration level of DG. Section 3 presents the modelling of DG penetration level based on capacity of distribution transformer. Section 4 shows the simulation results on fault analysis with DG, EVs and energy storage batteries. Section 5 concludes the paper.

\section{System Fundamentals}

In conventional radial distribution systems power flows in one direction from source to load. Protection devices are placed on feeders to detect faults and protect system equipment. The ordinary type of protection devices are thermo-magnetic switches, Moulded-Case Circuit Breakers (MCCBs), fuses, and over-current relays. Amongst these types, over-current relay is the most common protection device used to counteract abnormal currents in power systems [16]. Each protection device has to cover prescribed zone. In highly reliable network, coordination between protections devices are established to only isolate faulty zone and maintain healthy parts energized [17].

Fuses installed at the main feeder or lateral feeders in distribution networks operate when the fault current heats up and melts the fuse link. Time Current Characteristic (TCC) curves are used to describe the fuse link melting time. Fuses are used in conjunction with automatic reclosers to prevent damage during the event of a temporary fault and the extended time period of fault outages [18]-[19].

The advent of DG in conventional radial configurations causes a number of problems with the protective devices coordination. In radial systems, overcurrent protection is designed on the assumption that the fault current flows in one direction only, from the utility to the load. This assumption is no longer valid if DG is embedded in the network. In addition, the presence of DG in a network changes the short circuit level [20].

The type of DG connected to the system affect the short circuit level. The synchronous generator is the highest fault current contributor. Inverter interfaced DG type has the least amount of fault current contribution due to the controller limiters [21]. According to G83/2 standards [22]-[23] DG must remain connected for $0.5 \mathrm{sec}$ when the measured phase-phase voltage is less than $80 \%$ of the nominal value, and must remain connected (or "ride-through") for duration of $2.5 \mathrm{~s}$ when the measured voltage constrained between $80 \%$ and $87 \%$ of the nominal value. Reliability of power network can be increased if DG is 
configured to support back up islands during upstream utility source outages.

In distribution networks fuses are coordinated with recloser. This coordination is required in order to be able to save the fuse from blowing out in case of temporary faults. The purpose is to reduce power outages as it is not required to interrupt the system during temporary faults due to the fact that these faults are considered to be around $70 \%$ to $80 \%$ of the total faults. Fig. 1 shows an example of a part of a distribution network involving recloser and fuse with DG [24].

The radial distribution feeder is fundamentally passive so protective devices normally activate on steady state fault current. However, when DG is added to the feeder lateral, generation is closer to the load so less real power is required by the substation to provide the total real power demand. The power supply to meet demand is now the combination of power from substation $\mathrm{P}_{\mathrm{SUB}}$ and the power supplied from the $\mathrm{DG}\left(\mathrm{P}_{\mathrm{DG}}\right)$ given in eq. 1 and eq. 2.

$$
\begin{aligned}
& \sum\left(\mathrm{P}_{\text {load }}+\mathrm{P}_{\text {losses }}\right)=\mathrm{P}_{\text {demand }} \\
& \sum\left(\mathrm{P}_{\mathrm{DG}}+\mathrm{P}_{\mathrm{SUB}}\right)=\mathrm{P}_{\text {supply }}
\end{aligned}
$$

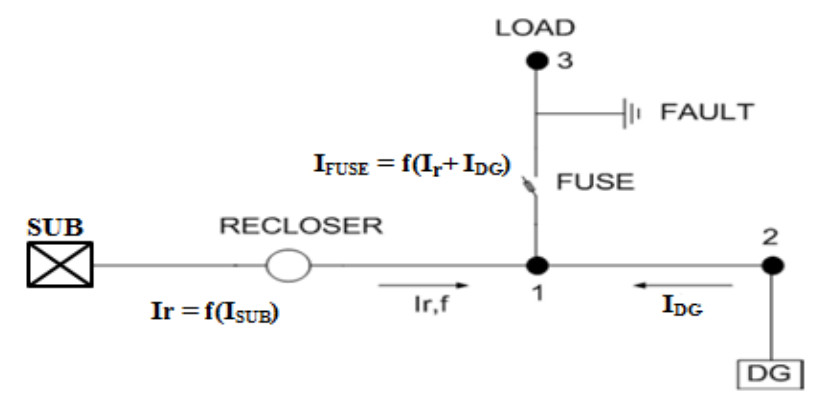

Fig. 1. Network with embedded generation.

The penetration of DG in the network will change the power characteristics of the network, contributing to fault currents which increase the fault current values and may cause failure of fuserecloser coordination. In Fig. 1, the fault current flowing through the recloser is only contributed by the substation (source), whilst the fault current flowing through the fuse is a sum of the currents from the DG and the substation. The increase in the fault current flowing through the fuse could be sufficient to initiate the blowing of the fuse before the recloser operation.
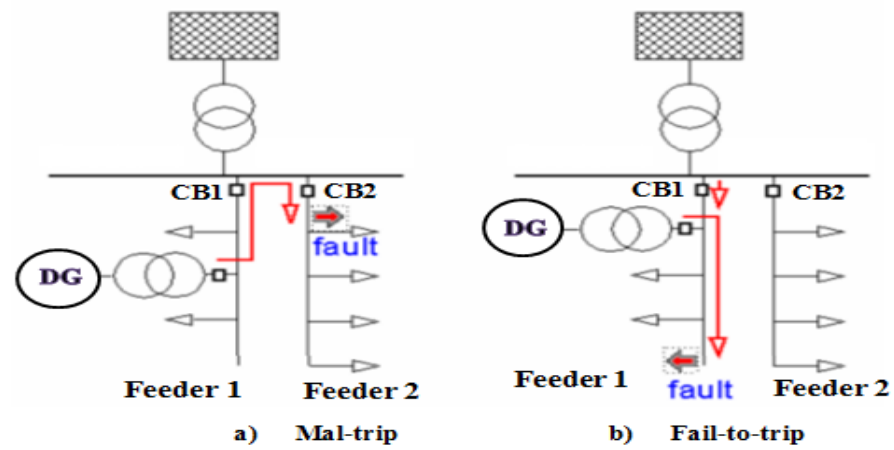

Fig. 2. Mal trip of feeder 1 during upstream fault (left) and fail to trip during down-stream fault (right) [23].

In future active distribution systems, the type of protection depends on the situation of the DG and its location in the network as the penetration of DG can change the configuration of the network. Protection systems can fail by unnecessarily removing a non-faulty component (mal-trip) or failure to remove a faulty component (fail-to-trip). In case of mal trip, a protection device detects the fault while it is outside 
its protection zone and trips unnecessarily. Fig. 2-a, shows this type of failure occurs when the DG feeds an upstream fault. Circuit breaker CB2 is the protection device that should trip whenever a fault occurs on feeder 2. However, CB1 at feeder 1 may trip unnecessarily due to the fault current contributed to the fault from the DG. Therefore, the reliability of the distribution network is reduced [25]. In contrast, CB1 may fail to trip for a downstream fault if a DG is connected as shown in Fig. 2-b [26]. The presence of DG results in the reduction of the fault current contribution from the feeder and therefore, the fault may not be cleared by CB1 [27]-[28].

\section{Modelling of DG Penetration Level Based on Capacity of Distribution Transformer}

In this paper, typical UK distribution network model discussed in [29] is used with penetration mainly from wind power and Photovoltaic (PV) generations. Typical summer home load profile is used with roof top PV (3 kW output power) at a bright sunny day of UK as shown in Fig. 3 [30]. Wind power generation data pattern is gathered from the weather station installed at roof top of Glasgow Caledonian University campus.

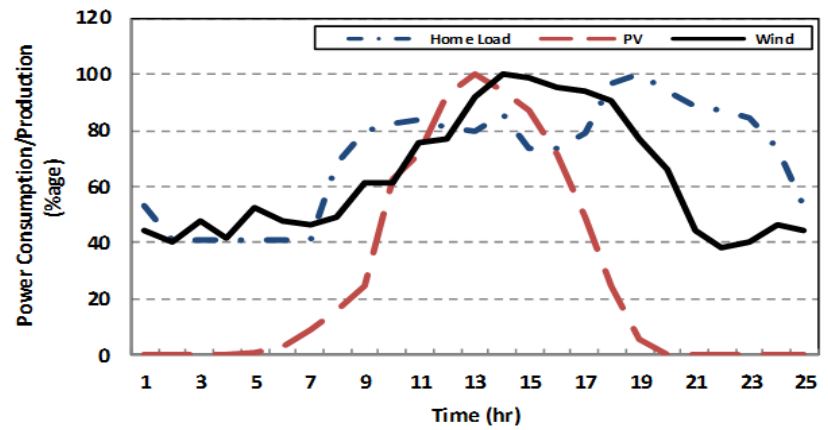

Fig. 3. Home load profile, PV and wind production for 24 hour period (summer season) in percentage.

It can be seen that there is a time shift between peak load demand and maximum capability of renewable generations. This behavior is considered in the modelling of DG penetration level addressed in this research.

In this research, percentage penetration level of DG is prepared with reference to $11 / 0.4 \mathrm{kV}, 500 \mathrm{kVA}$ distribution transformer rating. Penetration levels of DGs are analysed to measure the fault current. Two cases are presented below to evaluate penetration levels of DGs.

\subsection{Case 1: Total of 30\% DG penetration level, $13 \%$ from wind turbines and $17 \%$ from PV panels at the secondary side of transformer}

Individual penetration level percentage of wind turbines, PV panels and total DG percentage level with respect to the $500 \mathrm{kVA}$ transformer rating is analysed as shown in Fig. 4. It shows that there are opportunities to install more wind power so that the total percentage level of DG penetration can compensate for the load demand, particularly nearer the peak time.

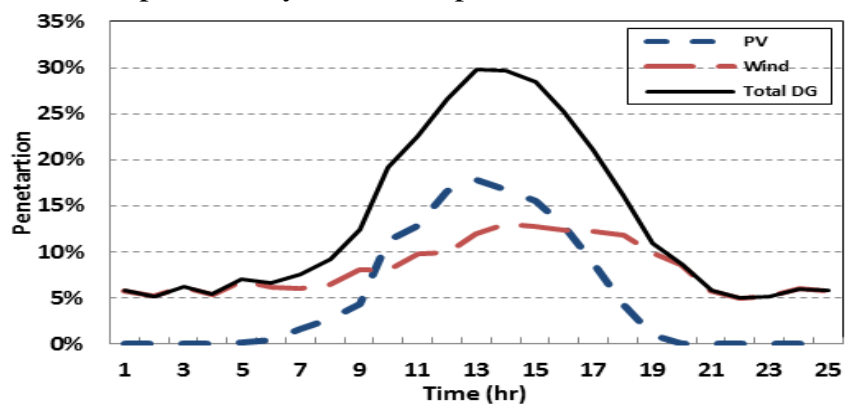

Fig. 4. \% DG penetration level (13\% Wind, 17\% PV). 
Fig. 5 represents total power flow from transformer after adding DG. In the middle of the day between 13 and $15 \mathrm{Hrs}$ with $30 \%$ DG power production, minor amount of reverse power is flowing at the transformer. The impact of this on the network operation particularly during the fault is discussed in Section 4.

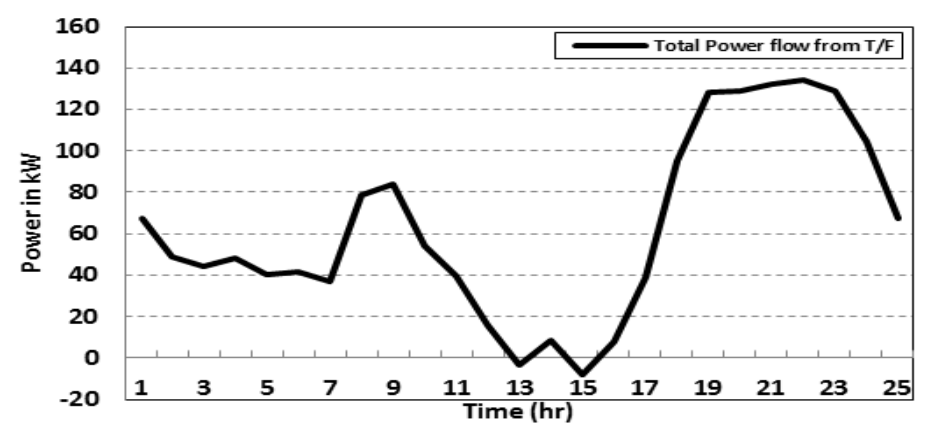

Fig. 5. Total power flow from $500 \mathrm{kVA}$ transformer for $30 \%$ penetration.

\subsection{Case 2: Total 103\% DG penetration Level, $78 \%$ from wind turbines and $25 \%$ from PV panels at the secondary side of the transformer}

Percentage DG penetration level at both ends of the day has enhanced from 5\% to more than $30 \%$. At mid-day, it has touched $103 \%$ of the transformer capacity as shown in Fig. 6 . These curves also indicate how the type of DG changes the total penetration level over the day. Utility companies can encourage customers to install wind turbines at residential places (LV side) so that DG penetration level is increased at both end of the day. High penetration level at mid-day can be shaved by charging and discharging batteries during off-peak/peak hours [31].

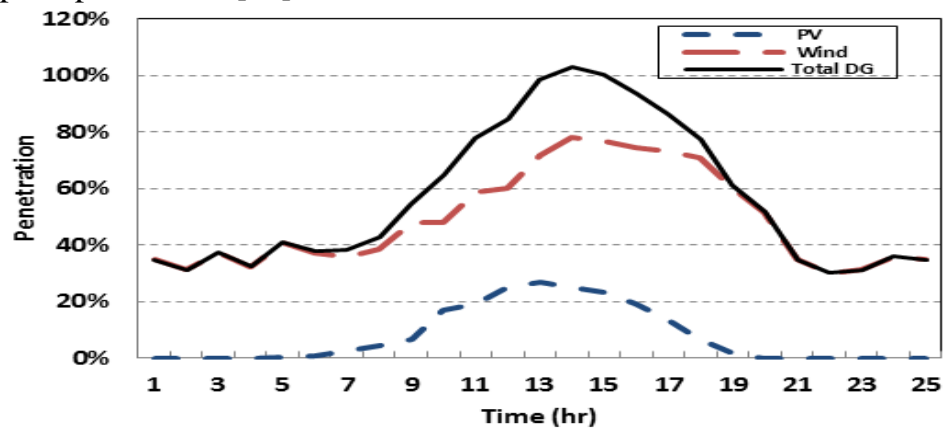

Fig. 6. \% DG penetration level (78\% Wind, 25\% PV).

With high penetration level of DGs reverse power flow will increase and reach its maximum level at the middle of the day as shown in Fig. 7. High amount of reverse power will impose significant technical barriers for the efficient and effective operation of existing distribution system protection. Increased fault current contribution from the DG will affect existing protective relaying scheme.

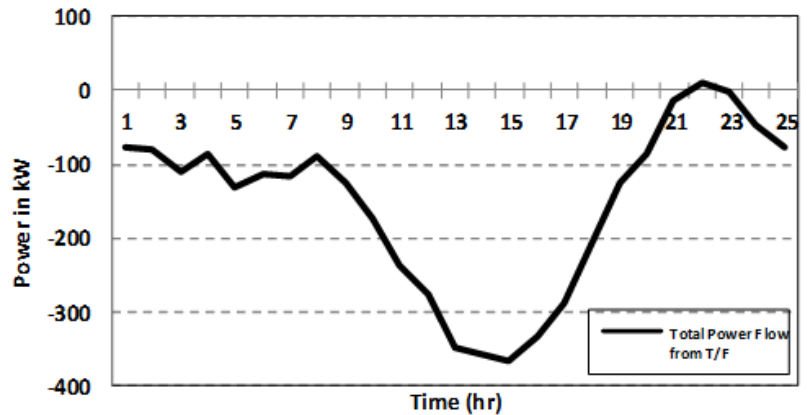

Fig. 7. Total power flow from $500 \mathrm{kVA}$ transformer for $103 \%$ penetration. 


\section{Simulation Results}

In UK distribution network, LV circuits are protected by High Rupturing Capacity (HRC) fuses as per British standard BS88 part 5 [32]. The LV fuse rating of a $500 \mathrm{kVA}$ transformer is given in Table 1.

Table 1. LV fuse rating

\begin{tabular}{c|c|c|c}
\hline $\begin{array}{c}\text { Transformer } \\
\text { Size } \\
(\mathbf{k V A})\end{array}$ & $\begin{array}{c}\text { Max } \\
\text { Fuse } \\
\text { size }\end{array}$ & $\begin{array}{c}\text { Nesidential non } \\
\text { electric heating }\end{array}$ & $\begin{array}{c}\text { Residential } \\
\text { electric heating \& } \\
\text { Industrial / } \\
\text { Commercial }\end{array}$ \\
\cline { 3 - 4 } & & $315 \mathrm{~A}$ & $400 \mathrm{~A}$ \\
\hline
\end{tabular}

The schematic diagram of the simulated UK distribution network is shown in Fig. 8. In this paper, single $11 / 0.4 \mathrm{kV}$ feeder is selected for the simulation studies. The 11/0.4 kV substation supplies 384 properties distributed along the outgoing radial feeders. At each case three phase fault is applied between node B11 and B12 and short circuit analysis is conducted. The fault is removed after 0.1 seconds so inverter-based DG remains connected during the fault time. The fault current contribution from upstream $(11 \mathrm{kV})$ side of the $500 \mathrm{kVA}$ distribution transformer is analysed. The current in both directions at the LV side of the transformer (bus B11) is measured. Short circuit analysis is firstly conducted on UK passive network and then high penetration level of DG is added to measure the flow of fault current from the 11 $\mathrm{kV}$ network towards the $400 \mathrm{~V}$ network.

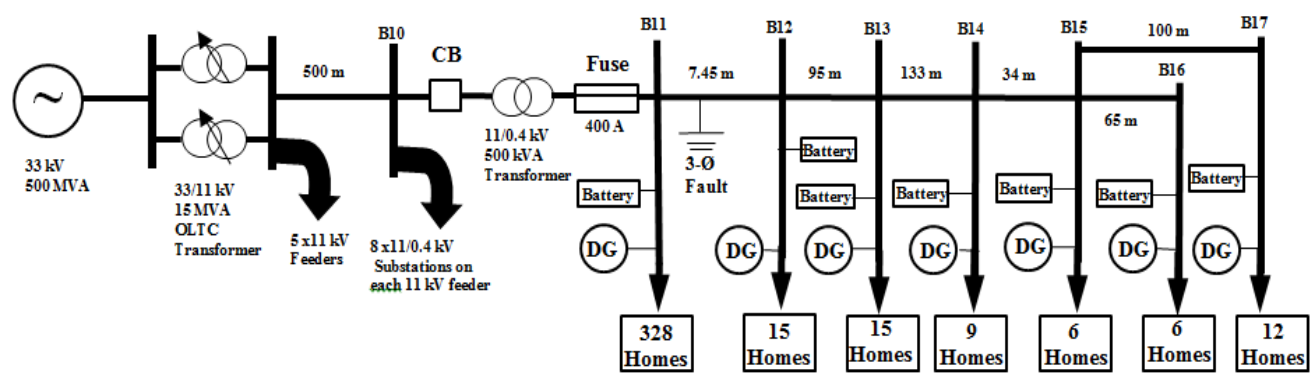

Fig. 8. 11/0.4 kV UK low voltage feeder.

EVs and energy storage batteries are used as remedial measures to confine the flow of short circuit current contributed by the DG at the $400 \mathrm{~V}$ network. Short circuit current is consumed by the batteries locally installed at homes. The flow of short circuit current towards the HV side or to adjacent laterals is significantly reduced. This will overcome mal trip and fail to trip phenomena due to high penetration level of DG.

\subsection{Short circuit analysis for domestic load without $D G$}

Typical daily load profile over 24 hours was simulated on UK distribution network. Phase current profile at the secondary side of transformer is shown in Fig. 9.

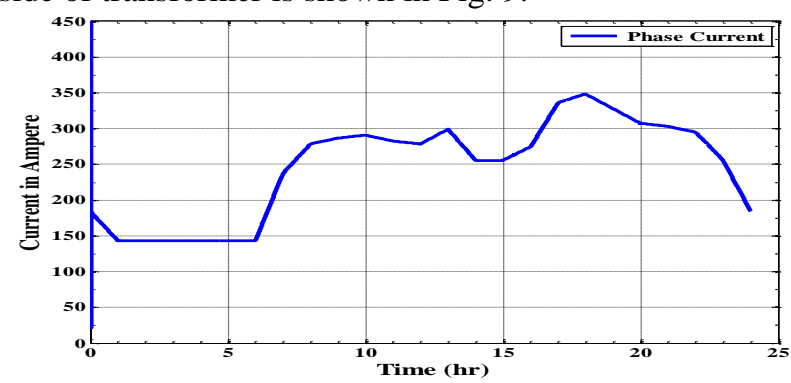

Fig. 9. Phase current profile at LV side of T/F. 
Three phase short circuit fault is applied at 5:00 am and cleared after 0.1sec. This is the time when minimum current is flowing towards residential properties. Fault current of 460 Amps is contributed by the substation as shown in Fig. 10. This will lead to relay pick up and the circuit breaker would trip before fuse is blown up.

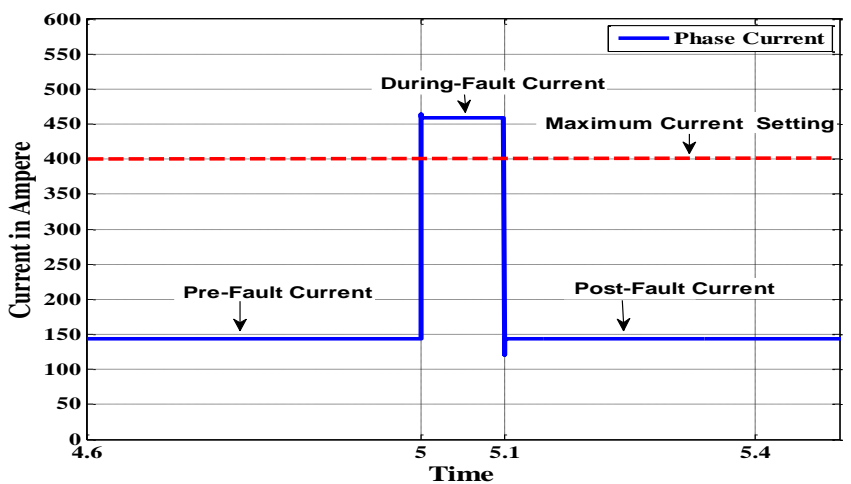

Fig. 10. Fault current contributed by the substation.

\subsection{Short circuit analysis with $78 \%$ wind and $25 \% \mathrm{PV}$}

High penetration level of DG injects power into the grid. High reverse power supply to $11 \mathrm{kV}$ network may exceed the pickup current of the relays. This would trip the CB as signaled by over current relay. Hence, at high penetration level of DG, rating of fuses and settings of CB may be required to update. Moreover, there could be a false operation of over current protection system which is designed for unidirectional power flow. To mitigate false current operation of relay due to reverse power flow, relay settings would be updated based on the maximum bi-directional current to ensure correct operation time faults [33].

Due to rise of voltage, DG owners are discouraged to drive their plants at full capacity [34]. In the German grid, only $70 \%$ of the $22 \mathrm{GW}$ solar is paid through feed-in-tariff for plants smaller than $30 \mathrm{~kW}$. Moreover, if the high reverse current from LV feeder to medium voltage feeder is not tackled properly residential DG owners would be forced to drive their units at low capacity.

Current profile of the transformer with DGs is shown in Fig. 11. At maximum DG penetration level i.e. mid-day, the reverse current reaches 550 Amps which is much higher than the rating of the fuse. Though this is not a fault but relay would pick up signal and trip the CB. The settings of the relays and rating of fuses need to be updated.

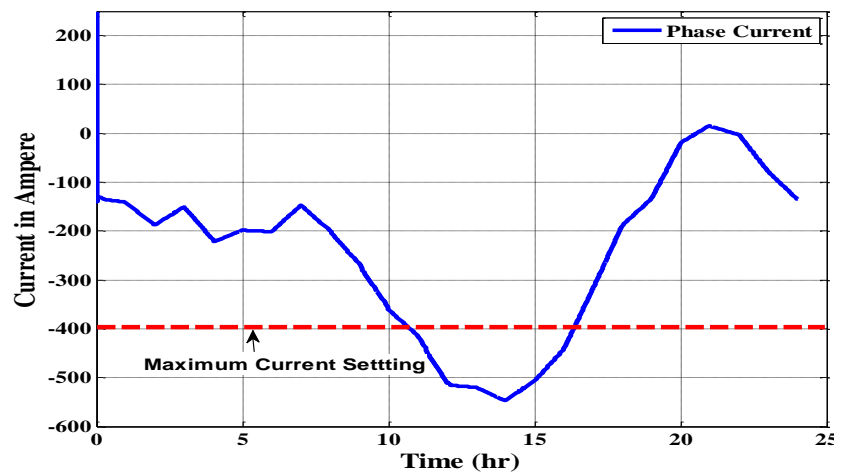

Fig. 11. Phase current profile at LV side of the transformer with DGs.

To evaluate the current contribution to the fault from the transformer, fault is applied at hour 14:00 for $0.1 \mathrm{sec}$ as shown in the Fig. 12. The reverse current is reduced from 550 Amps to around 320 Amps. In this case, DG would contribute to the upstream fault which results in the decrease of the transformer side current and the relay would be unable to detect the fault. 


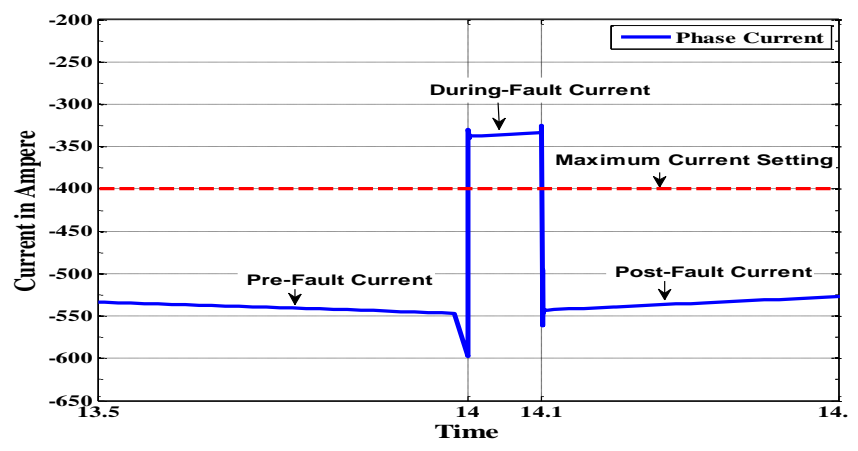

Fig. 12. Fault current contributed by the substation.

With high penetration level of DGs there is a possibility that relay may count high current as a fault, while fault current that is less than the relay settings would be counted as normal current. In below simulations, EVs and energy storage batteries are used to compensate the reverse power produced by DG.

\subsection{Short circuit analysis with $78 \%$ wind, $25 \% \mathrm{PV}$ and $39 \% \mathrm{EVs}$}

In the grid-to-vehicle (G2V) mode, EVs can operate as mobile active loads that increase the demand on the network during charging and as generators during discharging when operating in the Vehicle-ToGrid (V2G) mode. Standard $3 \mathrm{~kW}$ domestic chargers are used for 6 hours in this work [35]-[36]. $60 \mathrm{EVs}$ are charged one after the other except during the morning times at which the vehicles are leaving to offices and during the evening peak hours. During the 24 hrs load cycle, around 220-240 EVs are charged throughout the day. Fig. 13 shows the pattern of daily power consumption by EVs.

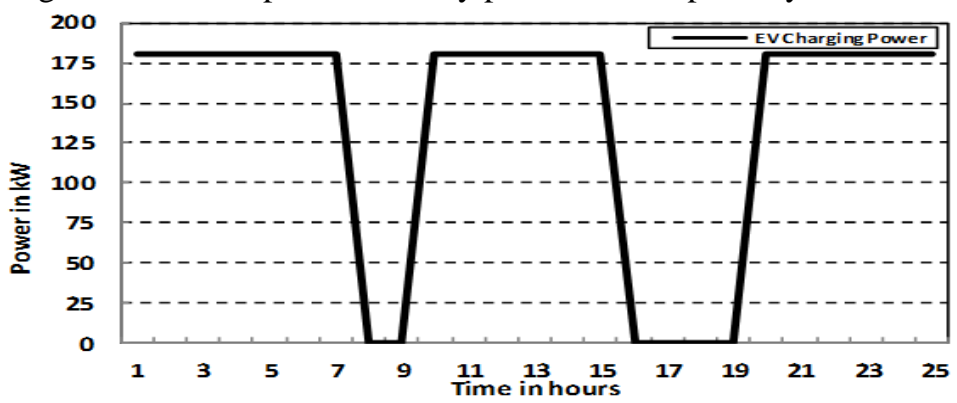

Fig. 13. Load profile of 60 EVs.

EVs acting as active load would reduce the reverse power flow towards $11 \mathrm{kV}$ network via transformer. The phase current is shown in Fig. 14. With EVs current at both ends of the days is flowing from $11 \mathrm{kV}$ to $400 \mathrm{~V}$ network and reverse current is reduced as compare to Fig. 11.

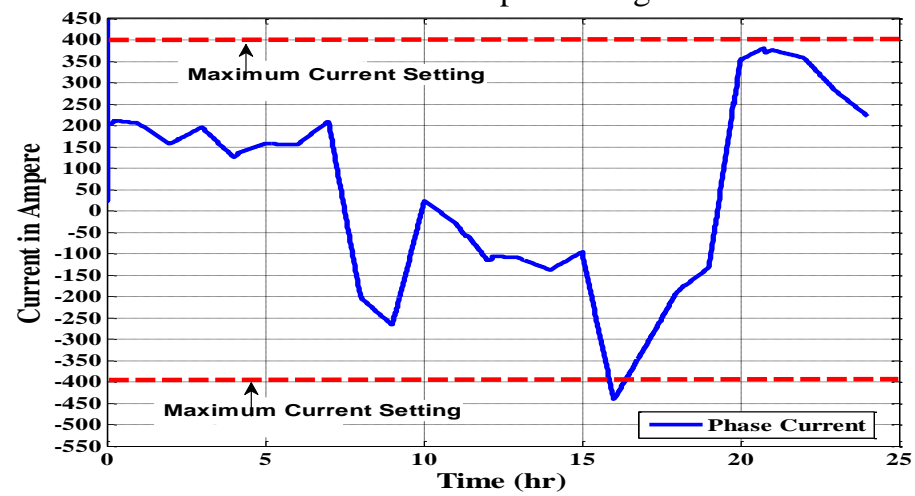

Fig. 14. Phase current profile at LV side of T/F with DGs and EVs. 


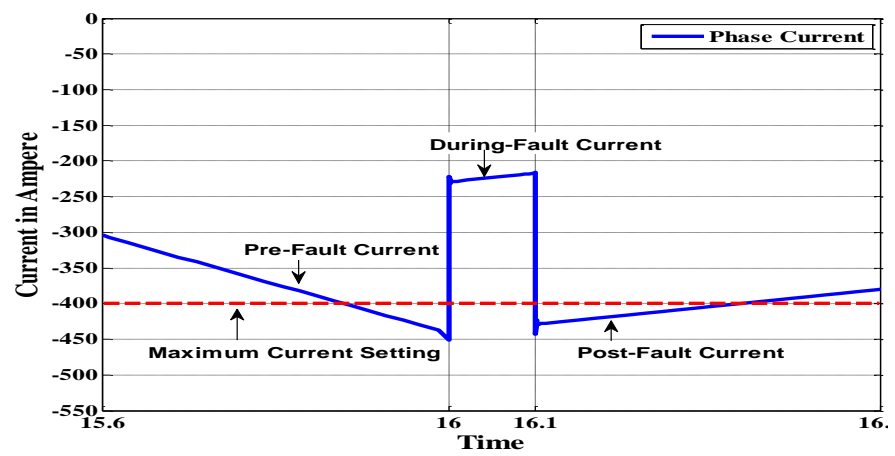

Fig. 15. Fault current contributed by the substation.

The phase current in reverse direction has exceeded the limit at 16:00 hrs. Relay will count this as a fault and open the circuit breaker. Fault is applied at hour 16:00 and cleared in 0.1 second as shown in the Fig. 15. As a result of the charging process the fault current is less than $-250 \mathrm{~A}$. Relay would be unable to distinguish between normal and fault current.

Grid connected wind and solar with storage batteries would reduce flow of reverse power and current. Compared to Fig. 12, the impacts of storage element is to reduce the short circuit current.

\subsection{Impact of standalone energy storage batteries on reverse power flow}

In this simulation 200 batteries with rating of $1 \mathrm{~kW}$ are distributed among 384 properties. In daily load cycle, batteries are required to charge when reverse power flow and discharge during both ends of the day i.e. from 00:00 to 08:00 hrs and 20:00 to 24:00 hrs. Fig. 16 shows power produced and consumed by the batteries during the charging and discharging cycle in $24 \mathrm{hrs}$.

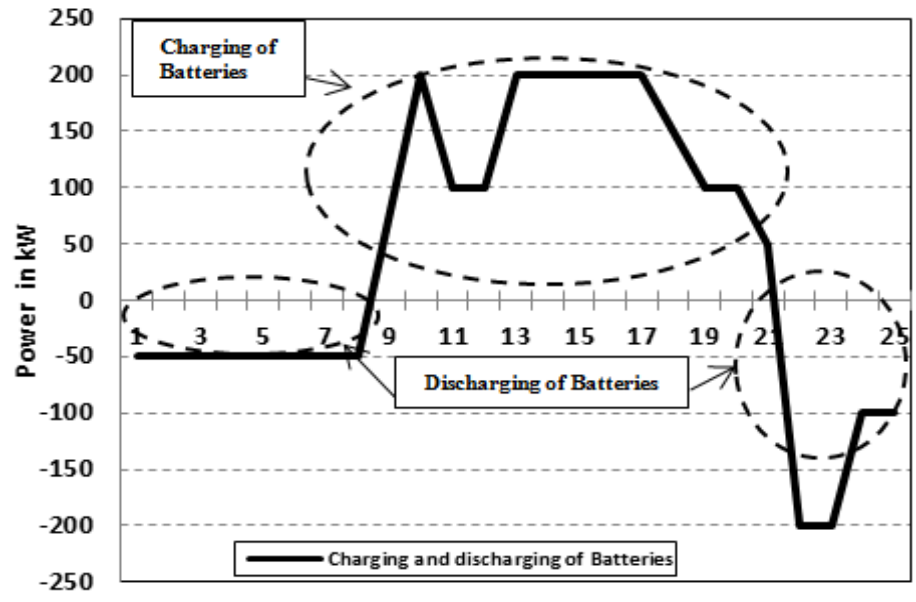

Fig. 16. Power consumed and produced by the batteries during charging and discharging period.

It is obvious that high production of power is required in mid-day to charge the batteries and less power generation at both ends of the day to discharge batteries. To achieve this, wind penetration level has to decrease and the PV penetration level has to increase. This will also allow the power to flow downstream for correct protection decision. Penetration level of wind is reduced from $78 \%$ to $26 \%$ and penetration level of PVs is increased from $25 \%$ to $53 \%$ as shown in the Fig. 17. With this scheme, power production at both ends of the day would decrease so batteries would be able to discharge. Batteries can be charged at mid-day when PV power production is maximum. 


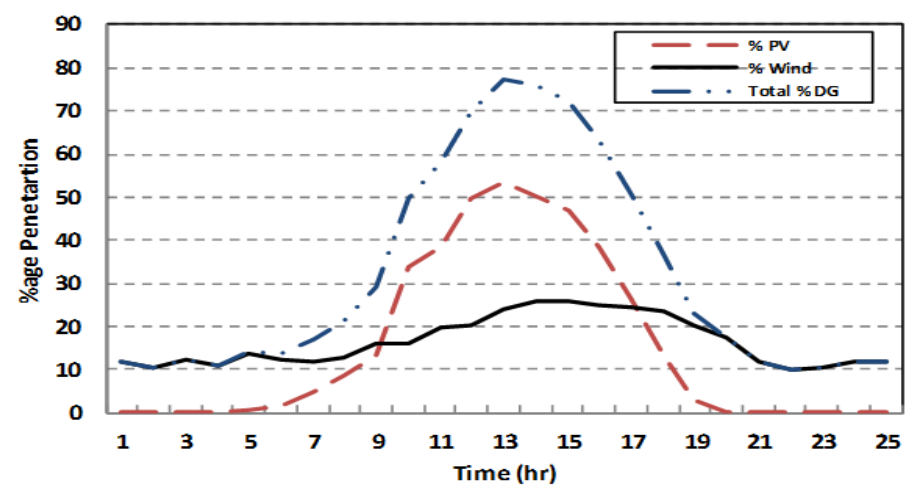

Fig. 17. \% DG penetration level (26\% Wind, 53\% PV).

Fig. 18 shows the power flow from the transformer. By proper penetration of DGs, EVs and energy storage batteries reverse power flow can be averted. High reverse power is not required as it will be required to change the protection schemes, relay settings as well as voltage rise.

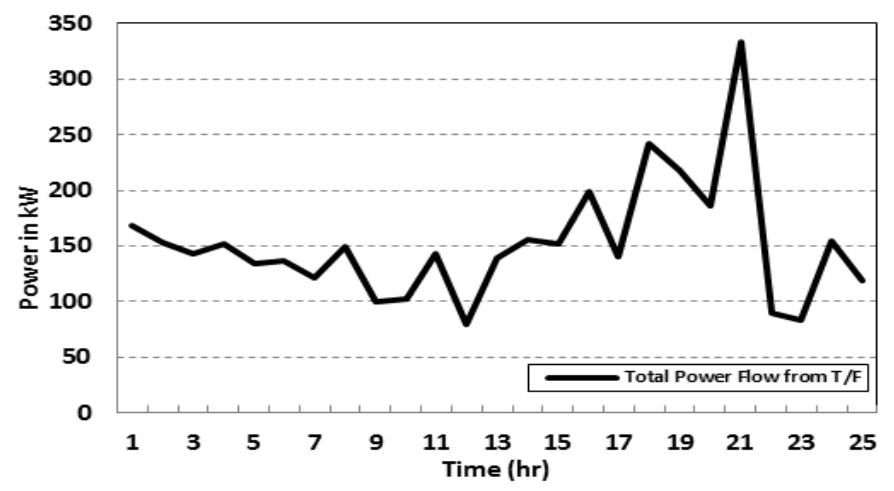

Fig. 18. Total power flow from $500 \mathrm{kVA}$ transformer with $26 \%$ Wind, $53 \% \mathrm{PV}, 39 \% \mathrm{EVs}$ and $40 \%$ batteries.

\subsection{Short circuit Analysis with $26 \%$ Wind, $53 \%$ PV, 39\% EVs and $40 \%$ Batteries}

Fig. 19 shows phase current at LV network after adding energy storage batteries.

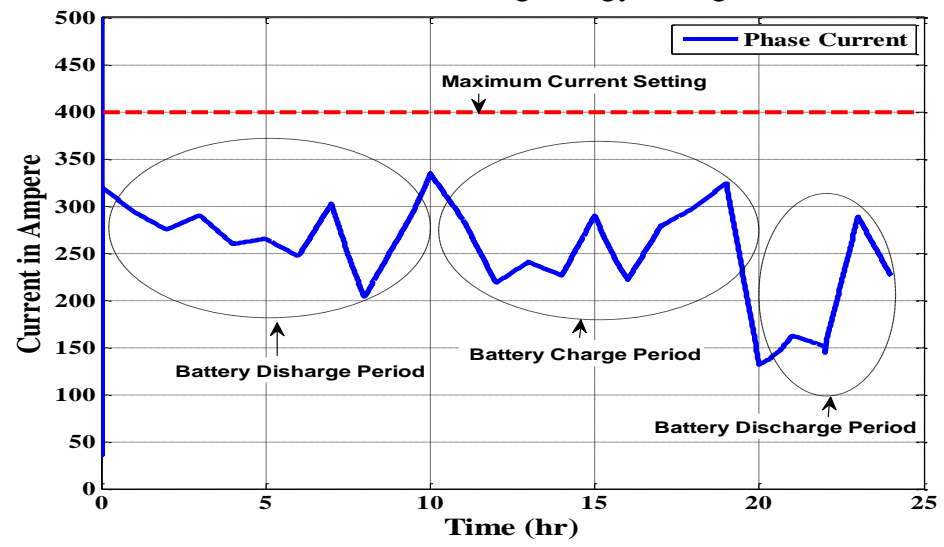

Fig. 19. Phase current profile at LV side of the transformer with DG, EVs and batteries.

Three phase fault is applied at 22:00 hrs and cleared after 0.1 sec as shown in Fig. 20. Fault current (450 Amp) is almost same as measured in Fig. 10 when there was no DG and uni-directional power flow in the radial distribution feeder. Batteries can be further optimally charged and discharged to add more DG based on fault current level. 


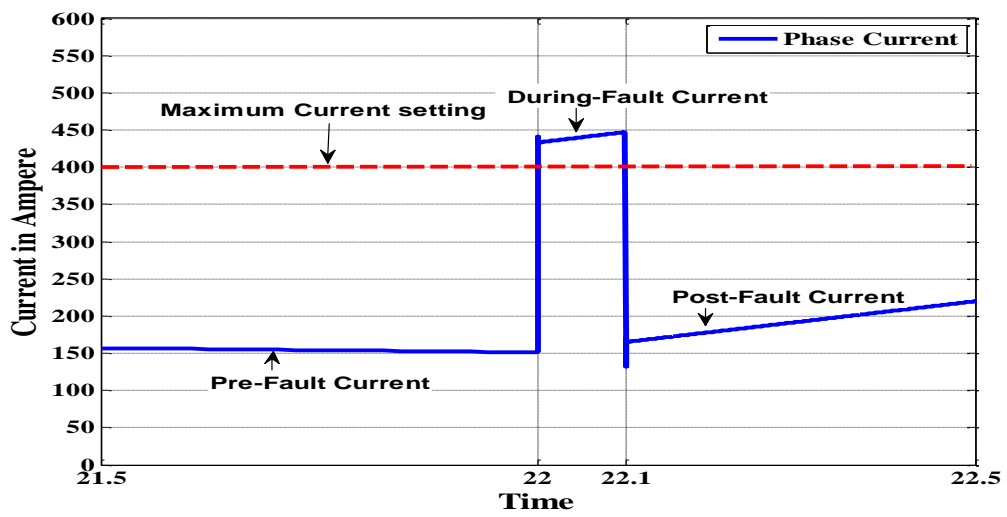

Fig. 20. Fault current contributed by the substation.

\section{Conclusion}

Renewable energies will be providing more and more of our electricity in the future. Large scale integration of wind and PV DG impacts the reliability and coordination of protection devices. Energy storage batteries are used as remedial measures. Whenever fault analysis is conducted for the future smart grid, EVs and batteries must also be integrated in system to observe the clear picture. EVs and energy storage batteries would allow continuous power flow to the downstream side of the transformer and help keeping the settings of protective devices fixed. DGs with batteries would allow suitable amount of fault current to flow from the transformer side, which would avoid mal-trip and fail to trip of relays. Without energy storage all customers cannot install DG domestically as reverse power could cause overloading of distribution transformer. The proposed scheme with proper scheduling of batteries, fuse and relay coordination would remain the same as in existing radial feeder protection scheme.

\section{References}

[1] Rahimi F, Ipakchi A. Demand response as a market resource under the smart grid paradigm. IEEE Trans. on Smart Grid., 2010; 1(1):82-88.

[2] Waseem I. Impacts of distributed generation on the residential distribution network operation. MSc thesis. Virginia Polytechnic Institute and State University. Virginia; 2008.

[3] Hadi, Azah, Hussain, Marjan. Impact of distributed generations on power system protection performance. International Journal of the Physical Sciences, 2011; 6(16):3999-4007.

[4] Barbier C, Maloyd A, Putrus G. Embedded Controller for LV Network with Ddistributed Generation. UK: Department of Trade and Industry; 2007.

[5] Lew D, Bird L, Milligan M, Speer B, et al.. Wind and Solar Curtailment. In: Proc. of International Workshop on Large-Scale Integration of Wind Power Into Power Systems as Well as on Transmission Networks for Offshore Wind Power Plants, 2013:1-7.

[6] Anderson R. (April, 2014). Energy storage: The key to a smarter power grid. [Online]. Available: http://www.bbc.com/news/business-27071303

[7] Energy Storage Keeping Smart Grids in Balance. Power and productivity for better world, ABB.

[8] Rentzing S. (April 2013). When will solar batteries become economical? [Online]. Available: http://www.solarenergystorage.org/en/wann-werden-solarakkus-wirtschaftlich-2/

[9] Paul, Erik, Brendan, Michael. The role of energy storage with renewable electricity generation. Research report. National Renewable Energy Laboratory, 2010.

[10] Bahadornejad M, Nair N. Solar PV, battery storage and low voltage distribution network: a discussion on the benefits of distributed battery storage. Power systems group, University of Auckland, 2013.

[11] Lucas A, Chondrogiannis S. Smart grid energy storage controller for frequency regulation and peak shaving, using a vanadium redox flow battery. International Journal of Electrical power and Energy Systems, Elsevier, 80(2016):26-36.

[12] Sivanandan S, Jaisiva S, Vinoth R, Mahendran A. Transient stability analysis of distributed generation. IJRET: International Journal of Research in Engineering and Technology, 2014. 
[13] Akbarimajd A, Mirzayi M. Voltage and frequency control in microgrid by battery energy storage. Int. J. Rev. Life. Sci., 2014; 4(12):35-47.

[14] Bhuttoa GM, Bak-Jensena B, Mahata P. Modeling of the CIGRE low voltage test distribution network and the development of appropriate controllers. International Journal of Smart Grid and Clean Energy, 2012.

[15] Chua KH, Lim YS, Morris S. Battery energy storage system for peak shaving and voltage unbalance mitigation. International Journal of Smart Grid and Clean Energy, 2013.

[16] Holmes J, Gers JM. Protection of Electricity Distribution Networks. United Kingdom: Power and Energy Series 47; 2004.

[17] Khan UN. Impact of Distributed Generation on Distributed Network. 2008.

[18] The Electricity Association. Power System Protection Vol. 3: Application. The Institution of Electrical Engineer, 1995.

[19] Anderson PM. Power System Protection. Wiley-IEEE Press; 1998.

[20] Barker PP, Mello RWD. Determining the impact of distributed generation on power systems: part 1 - radial distribution systems. Power Engineering Society Summer Meeting, 2000.

[21] Martin-Arnedo J, Martinez JA. Impacts of distributed generation on protection and power quality. 2009.

[22] Gatta FM, Iliceto F, Lauria S, Masato P. Modelling and computer simulation of in dispersed generation in distribution networks. Measures to prevent disconnection during system disturbances. Presented at: 2009 IEEE Power Tech Conference.

[23] Operations Directorate of Energy Networks Association. Recommendations for the Connection of Type Tested Small-scale Embedded Generators (Up to 16A per Phase) in Parallel with Low-Voltage Distribution Systems. Engineering Recommendation G83 Issue 2, 2012.

[24] Brahma S, Girgis A. Effect of distributed generation on protective device coordination in distribution system. Presented at: 2001 Conference Power Engineering.

[25] Desus J, Grenard S, Bollen MHJ, Häger M, Sollerkvist F. Effective impact of DER on distribution system protection. Presented at: 2007 19th International Conference On Electricity Distribution.

[26] Sarabia AF. Impact of distributed generation on distribution system. MSc thesis. Aalborg University. Denmark; 2011.

[27] Kauhaniemi K, Kumpulainen L. Impact of distributed generation on the protection of distribution networks. Presented at: 2004 IEEE International Conference on Developments in Power System Protection.

[28] Gallery T, Martinez L, Klopotan D. Impact of distributed generation on distribution network protection. ESBI Engineering \& Facility Management.

[29] Suwanapingkarl P. Power quality analysis of future power network. PhD thesis, University of Northumbria. Newcastle, UK; 2012.

[30] Hernándeza JC, Medina FJA. Impact comparison of PV system integration into rural and urban feeders. Energy Conversion and Management, 2008; 49(6):1747-1765.

[31] Poullikkas A. Renewable and Sustainable Energy Reviews. Renewable and Sustainable Energy reviews, 2013.

[32] Haggis T. Network Design Manual. 2006.

[33] Barsoum N, Chai ZL. Simulation of power flow and protection of limited bus grid systems with injected solar power. Energy and Power Engineering, 2013; 5(1):59-69.

[34] Stetz T, Marten F, Braun M. Improved low voltage grid integration of photovoltaic systems in Germany. IEEE Trans. Sustainable Energy, 2013; 4(2):534-542.

[35] Koyanagi F, Inuzuka T, Uriu Y, Yokoyama R. Monte Carlo simulation on the demand impact by quick chargers for electric vehicles. In Proc. of IEEE Power Engineering Society, 1999:1031-1036.

[36] MacDonald M. System integration of additional micro generation. Department of Trade and Industry, 2004. 